\title{
ULTRASONOGRAPHIC EVALUATION OF LOWER UTERINE SEGMENT THICKNESS IN PREGNANT WOMEN WITH PREVIOUS CESAREAN SECTION: A SYSTEMATIC REVIEW
}

\author{
Muhammad Azeem (Correspondence Author) \\ MID, MSDU* \\ University Institute of Radiological Sciences and Medical Imaging Technology Faculty of Allied \\ Health Sciences, The University of Lahore (main campus), Lahore. Pakistan \\ Email:Azeembutt121@yahooo.com
}

Abdul Hanan

The University of Lahore (main campus), Lahore. Pakistan

E-mail:hannan.naeem95@gmail.com

\author{
Dr. Syeda Khadija \\ Phd* MSDU(Ultrasound)
}

Assistant professor Department (UIRSMIT) FAHS

E-mail:syeda.khadija@rsmi.uol.edu.pk

Syed Shah Hussain

Bs(hons) MIT, MSMIT, PhD-MIT*

E-mail: gillanisyed2112@gmail.com

Iqra Shafi

Bachelors in Medical Imaging Technology, Student, Department of Allied Health Sciences, Superior College Lahore, University Campus, 17-KM Raiwaind Road, Kot Arain, Lahore,Pakistan

Iqrashafi607is4443704@gmail.com

Syed zain Ul Abidin

Bs(hons) MIT, MSMIT, PhD-MIT*

The University of Lahore (main campus), Lahore. Pakistan

Syedzaingillani01@gmail.com

\begin{abstract}
Background:

Nowadays it's a big problem of lower uterine thickness in pregnant women that causes a lot of problems. Lower uterine segment thickness is a strong predictor for uterine scar defect in women with prior caesarian section. Lower segment cesarean section (LSCS) rates are raising throughout the world. Women with previous one cesarean can undergo either the trial of vaginal birth or elective repeat cesarean section in their next pregnancy. The study aims to assess the diagnostic accuracy of sonographic measurement of lower uterine segment thickness in pregnant women So there we are going to evaluate lower uterine segment thickness in pregnant women sonographically by using transabdominal and transvaginal approaches as well.
\end{abstract}

Objective: To evaluate lower uterine segment thickness in pregnant women with previous caesarian section by sonography.

\section{Materials and Methods:}


An electronic data base search was performed through the searches using PubMed, Google Scholar, international Journal of Gynecology \& obstetrics and some other online journals and medical websites with the range from 2000-2021. All studies included in the research was in English language. Articles which had descriptive studies related to sonographic features of lower uterine segment thickness of pregnant women with C-section.

\section{Results:}

Research data of 200 patients in all studies showed that Transvaginal ultrasound provided greater reliability in LUS measurements than did transabdominal ultrasound. The use of three-dimensional ultrasound improved significantly the reliability of the LUS muscular thickness measurement obtained transvaginal

\section{Conclusion:}

We identified certain sonographic patterns that can accurately shows the lower uterine segment thickness in pregnant women with previous caesarian section.

Keywords: LUS lower uterine segment thickness, Transabdominal and Transvaginal ultrasonography, Pregnancy, Caesarian Section

DOI: $10.7176 / \mathrm{JHMN} / 93-07$

Publication date:September $30^{\text {th }} 2021$

\section{1. introduction}

The lower uterine segment, actually, is defined as the section of the uterine musculature which must go through circumferential dilatation during labor, its extent being dependent upon the size of the presenting part and its level in the uterine cavity. Uterine scar dehiscence is one of the complications associated with previous LSCS, in which there is disruption and separation of previous scar To all the more likely survey the danger of uterine crack, a few creators have proposed sonographic estimations of lower uterine section (LUS) thickness close to term, accepting that there is a converse relationship be tween's LUS thickness and the danger of a uterine scar deformity. Thusly, this evaluation for the administration of ladies with past cesarean segment may build security during work by choosing ladies with the most reduced danger of uterine rupture. Vaginal birth after cesarean area (VBAC) has become a basic piece of current obstetrics with in excess of 100,000 VBACs accomplished every year from one side of the country to the other (1). In spite of this, it stays a disputable issue. In spite of the fact that it has been accounted for as protected and has added to a decreased cesarean conveyance (CS) rate 2, 3, 4, VBAC is related with a danger of uterine break (5). Since the maternal and fetal results of uterine break can be not kidding and conceivably dangerous 6,7 , the legitimate determination of patients would be a significant essential. It is by and large thought to be that, among deliberately chose patients who have full cooperation in dynamic, most ladies with one past cross over LSCS are reasonable contender for VBAC and ought to be offered a preliminary of work 8, 9. Albeit the adequacy and security of VBAC have been shown 2, 4, as far as anyone is concerned, there are no dependable strategies to anticipate the dangers of uterine crack in this gathering of patients. Studies have shown that the danger of uterine crack within the sight of an imperfect scar is connected straightforwardly to the level of diminishing of the LUS 10,11.

Three layers of the lower uterine section (LUS) can be recognized on ultrasound: the chorioamniotic film with decidualized endometrium; the center solid layer; and the uterovesical peritoneal reflection compared with muscularis and mucosa of the bladder With high achievement paces of up to $87 \%$, vaginal birth (VBAC) is oftentimes offered to ladies after past cesarean area (CS) $[12,13]$. An uncommon complexity is uterine crack during birth. Notwithstanding its low rate of $0.4-0.9 \%$ yet in light of its staggering result, hazard delineation by extra pre-birth ultrasound diagnostics of the lower uterine section (LUS) has been an intriguing issue for the last 20 years $[14,15,16]$. Today, a relationship between LUS thickness and the danger for uterine break can be accepted, yet neither helpful reference esteems nor even the advantage of pre-birth LUS thickness estimation have been obviously exhibited [15,17]. Different examinations have explored diverse estimation approaches utilizing 2D-and 3D-procedures in transvaginal and transabdominal ultrasound $[12,16,18,19,20]$. The conflicting outcomes with wide-going reference esteems for the slender design of the LUS and experience from clinical routine raise sensible questions about the convenience of LUS thickness estimation for birth determination in clinical practice [21]. By the by, ultrasound is the main line noninvasive imaging procedure and permits an outline of morphology and measurements of the scarred uterus after CS [17]. We theorize that the current conventions are inadequate however may be improved if explicit qualities of the LUS would be considered in diagnostics. 


\subsection{Material and Methods}

With high achievement paces of up to $87 \%$, vaginal birth (VBAC) is oftentimes offered to ladies after past cesarean area (CS) $[12,13]$. An uncommon complexity is uterine crack during birth. Notwithstanding its low rate of $0.4-0.9 \%$ yet in light of its staggering result, hazard delineation by extra pre-birth ultrasound diagnostics of the lower uterine section (LUS) has been an intriguing issue for the last 20 years $[14,15,16]$. Today, a relationship between LUS thickness and the danger for uterine break can be accepted, yet neither helpful reference esteems nor even the advantage of pre-birth LUS thickness estimation have been obviously exhibited [15,17]. Different examinations have explored diverse estimation approaches utilizing 2D-and 3D-procedures in transvaginal and transabdominal ultrasound $[12,16,18,19,20]$. The conflicting outcomes with wide-going reference esteems for the slender design of the LUS and experience from clinical routine raise sensible questions about the convenience of LUS thickness estimation for birth determination in clinical practice [21]. By the by, ultrasound is the main line noninvasive imaging procedure and permits an outline of morphology and measurements of the scarred uterus after CS [17]. We theorize that the current conventions are inadequate however may be improved if explicit qualities of the LUS would be considered in diagnostics

\subsubsection{Sonography}

The sonographic examinations were performed with an Accuvix (Medison Co., Ltd. Seoul, Korea) machine equipped with a 4-7-MHz transabdominal (3D4-7EK) and a 5-8-MHz transvaginal (3D5-8EK) probe. Measurements were performed by two sonographers, Observer 1 (D.A.B.) and Observer 2 (F.M.P.G.). The ultrasound scans followed this sequence: primary, transabdominal evaluation (Figure $1 \mathrm{a}$ and $\mathrm{c}$ ) was performed with the woman in a supine position with a comfortably full bladder. One observer stored two images of the entire LUS thickness measurement (one cursor positioned at the urine-bladder interface and the other at the decidua-amniotic fluid interface 5 ) and one 3D dataset, and then repeated this process. When this observer had completed the evaluation he left the examination room and the other observer entered to perform the same steps. After the transabdominal examinations were complete, the transvaginal examination (Figure $\underline{1} b$ and $d$ ) was performed with the woman in the lithotomy position, within $20 \mathrm{~min}$ after voiding her bladder $\underline{3}$. The same schedule of examinations was performed by the two observers, this time measuring the LUS muscular layer (one cursor positioned at the bladder-muscular interface and the other at the muscular-decidua interface 6 ). The time taken between first placement of the probe on the abdomen or inside the vagina until storage of the first image (time to identify and measure LUS) was noted. The order of observers was swapped for each new patient.

Figure Images demonstrating measurement of the entire thickness of the lower uterine segment (LUS) by transabdominal two-dimensional (a) and three-dimensional (c) ultrasound, and of the muscular layer of the LUS by tranvaginal two-dimensional (b) and three-dimensional (d) ultrasound.

After all examinations had been completed, the two observers manipulated their acquired volumes on the multiplanar display, trying to avoid obliquity and searching for the thinnest portion of the LUS. They were blinded to the measurement by a label placed on the numeric display. For each observer, two images of the LUS measurement for each method were stored from each of the two previously recorded 3D datasets. The time spent between opening the 3D dataset and storage of the first LUS measurement image was also noted.

Transvaginal and transabdominal techniques:

The transvaginal approach was more reliable than was the transabdominal one (Table 1 ). The means of the absolute differences were significantly lower for the transvaginal LUS muscular thickness measurement for all comparisons. The proportion of differences $<1 \mathrm{~mm}$ was significantly higher for the transvaginal approach on all intra- and interobserver evaluations. The ICCs were higher for the transvaginal approach on all comparisons. The $95 \%$ limits of agreement were also narrower for the transvaginal approach both for 2D and 3D ultrasound

\subsubsection{Results and Discussion}

In the result, we found that ultrasonographic LUS muscular thickness assessed by transvaginal ultrasound was more reliable than entire LUS thickness measured by the transabdominal approach. Nonetheless, one should consider that the association between thin LUS muscular thickness measurement obtained by transvaginal ultrasound and the risk of uterine rupture has only been suggested: all patients evaluated by studies in which LUS was assessed by the transvaginal approach underwent Cesarean section and only uterine dehiscence was observed. The actual association between thin LUS measurement and uterine rupture (in women undergoing labor, with some undesirable uterine ruptures) has been assessed only using the transabdominal approach. The use of $3 \mathrm{D}$ ultrasound requires specific training of sonographers, longer examination time and ultrasound 
machines and probes with 3D capability. Nevertheless, the use of three-dimensional ultrasound should be considered, since it resulted in a significant improvement in reliability

Twelve eligible studies including 1834 women were identified. Uterine scar defect was reported in a total of 121 cases $(6.6 \%)$. Seven studies examined the full LUS thickness only, four examined the myometrial layer specifically, and one examined both measurements. Weighted mean differences in LUS thickness and associated 95\% confidence intervals between women with and without uterine scar defect were calculated. Summary receiver operating characteristic (SROC) analysis and summary diagnostic odds ratios (DOR) were used to evaluate and compare the area under the curve (AUC) and the association between LUS thickness and uterine scar defect. Women with a uterine scar defect had thinner full LUS and thinner myometrial layer (weighted mean difference of $0.98 \mathrm{~mm} ; 95 \%$ CI 0.37 to $1.59, \mathrm{P}=0.002$; and $1.13 \mathrm{~mm} ; 95 \%$ CI 0.32 to $1.94 \mathrm{~mm}, \mathrm{P}=0.006$, respectively). SROC analysis showed a stronger association between full LUS thickness and uterine scar defect (AUC: $0.84+/-0.03, \mathrm{P}<0.001$ ) than between myometrial layer and scar defect (AUC: $0.75+/-0.05, \mathrm{P}<0.01$ ). The optimal cut-off value varied from 2.0 to $3.5 \mathrm{~mm}$ for full LUS thickness and from 1.4 to 2.0 for myometrial layer.

There were a total of 5874 women in all studies, 20 women were missing delivery information. Trial of labor was attempted in $2680(45.8 \%)$, and $3174(54.2 \%)$ had a repeat elective cesarean section. In the trial of labor group, $1768(66.0 \%)$ women had a vaginal delivery and $912(34.0 \%)$ required an emergency cesarean section. There were 21 cases $(0.4 \%)$ of uterine rupture reported: 12 women who delivered by emergent cesarean section, five who had a vaginal delivery and four who had an elective cesarean section. There were 361 cases $(6.2 \%)$ of uterine dehiscence reported in 55 women who delivered by emergent cesarean section, two who had a vaginal delivery and 304 who had an elective cesarean section. The remaining $5472(93.5 \%)$ women had no reported uterine defect at the time of delivery. Twenty women were lost to follow up and delivery information was not reported.

Cheung announced that the clinical use of the LUS estimation in the administration of VBAC stays questionable. Clinical involvement in the utilization of the LUS estimation in anticipating uterine break and overseeing VBAC is restricted. Having a public library to record information and survey all instances of uterine burst would speed up the gathering of involvement regarding this matter. The current investigation proposes that sonographic LUS assessment is conceivably fit for distinguishing those patients with a meager or imperfect LUS, which could convey a higher danger of resulting crack when a preliminary of VBAC is endeavored. In the event that the thickness of the LUS is more than $2.5 \mathrm{~mm}$, the chance of dehiscence during the ensuing preliminaries of work is exceptionally little and a safe vaginal conveyance can be achieved 22 .

Bujold discovered full lower uterine portion thickness was related with uterine crack (region under the bend 0.88 , $95 \%$ CI $0.79-0.98 ; \mathrm{P}=0.02$ ) and uterine scar imperfection (territory under the bend $72 \%, 95 \%$ CI $53-90 ; \mathrm{P}=$ 0.03 ), yet myometrial thickness was not (region under the bend $0.66,95 \% \mathrm{CI} ; 0.34-0.98 ; \mathrm{P}=0.16$ ) 23 Rozenberg et al. announced a critical connection between the transabdominal sonographic estimation of the whole LUS thickness in ladies close to term who had a past Cesarean segment and the danger of uterine burst or dehiscence, the division of the solid layer with an unblemished serosa. No uterine break or dehiscence was noted when the whole LUS thickness was $>4.5 \mathrm{~mm}$. Besides, the danger of uterine burst or dehiscence was $0.66 \%$ when this estimation was $\geq 3.5 \mathrm{~mm}$, contrasted and $11.7 \%$ in ladies who had a LUS thickness $<3.5 \mathrm{~mm} .24$

Cheung announced that a cutoff thickness of $1.5 \mathrm{~mm}$ had an affectability of $88.9 \%$, an explicitness of $59.5 \%$, a PPV of $32.0 \%$, and a NPV of $96.2 \%$ in foreseeing a paper-meager or dehisced LUS. It is along these lines clear that the strategies utilized for estimating the LUS thickness and recognizing uterine deformities have not been steady among various investigations, albeit a few examinations appear to give great outcomes with various estimation methods.

There was a positive connection be tween's intraoperative evaluating of the LUS and its thickness by US. This shows that, the lower the LUS thickness, the higher the danger of scar dehiscence. The general danger of dehiscence at the LUS thickness underneath or equivalent to the basic cutoff esteem " $2.5 \mathrm{~mm}$ " utilizing TA U/S was $92.9 \%$ and it was $7.1 \%$ for thicknesses more than $2.5 \mathrm{~mm}$.[25]

Many studies have been done to assess the scar thickness by ultrasound. The lower segment scar is visible in only $30 \%$ of the patients. 9 Studies have suggested that there is an inverse relationship between scar thickness, assessed sonographically, and risk of uterine rupture.10,11 The risk factors associated include induced labour,12,13 reduced inter-delivery interval,14 the number of previous cesarean, type of closure of uterus, 15 
previous vaginal delivery, maternal age, gestational age at delivery, and fetal birth weight.16,17 Sonographic and intraoperative analyses show a p-value of 0.001 , which is significant. Based upon this findings, ultrasound can be used to assess the LUS and this modality can be used in third trimester in those cases where trial of labour after previous LSCS is intended. This finding is supported by the findings of Mohammad et al.18 Risk of thinning, dehiscence or rupture of scar is based upon the ultrasound appearance of LUS and its measurement. Suzuki et al. and Fukude et al. also supported these findings.19,20 Transabdominal ultrasounds was used in our study to assess lower uterine segment thickness or thinness. Suzuki et al., Fukude et al., and Rozenberg et al. also used transabdominal ultrasound to assess previous scar.19-21 While Gotoh et al. used tranvaginal ultrasound to assess the lower segment scar

Between October and December 2006, 30 pregnant women who had had at least one previous Cesarean section and were between 36 and 39 weeks' gestation were enrolled into the study at Escola de Ultra-sonographies e Reciclagem Médica de Ribeirão Preto. All women had singleton pregnancies in cephalic presentation. The women ranged in age from 21.3 to 35.2 (mean $\pm \mathrm{SD}, 27.4 \pm 3.5$ ) years. Twelve $(40 \%)$ women had previously had only one Cesarean section, 10 (33.3\%) women had previously had two, six (20\%) women had previously had one Cesarean section and one vaginal delivery and two $(6.7 \%)$ women had previously had one Cesarean section and two vaginal deliveries. By the time of the LUS evaluation, the gestational age ranged from $36+4$ weeks to $38+3$ weeks. This was a study of 30 pregnant women who had had at least one previous Cesarean section and were between 36 and 39 weeks' gestation, with singleton pregnancies in cephalic presentation. Sonographic examinations were performed by two observers using both $4-7-\mathrm{MHz}$ transabdominal and 5-8-MHz transvaginal volumetric probes. LUS measurements were performed using two- and three-dimensional ultrasound, evaluating the entire LUS thickness transabdominally and the LUS muscular thickness transvaginal. Each observer measured the LUS four times by each method

\subsubsection{Limitations}

There is possibility of various complications related to the uterine scar after C-section, including uterine scar dehiscence, uterine rupture, abdominal and pelvic adhesions, uterine synechiae, ectopic pregnancy, anomalous location of the placenta, placental invasion, and-rarely-vesicouterine or uterocutaneous. There is a need to find out proper frequency of such affected patients by ultrasonographic evaluation of lower uterine segment thickness after c section. So we can have necessary activities to manage it.

\subsubsection{Conclusin}

Ultrasonographic measurement of the LUS muscular thickness transvaginal appears more reliable than does that of the entire LUS thickness transabdominally. The use of three-dimensional ultrasound should be considered to improve measurement reliability. There lower segmental thickness is measured and accurately evaluated by TVS.

\subsubsection{Acknowledgement:}

I'm really grateful to my teacher Dr. Syeda Khadija for her immense support and guidance regarding my research.

\subsubsection{Conflict of interest:}

There was no known conflict of interest among all the authors of this research study.

\section{References}

1. Cheung VY. Sonographic measurement of the lower uterine segment thickness: is it truly predictive of uterine rupture? J ObstetGynaecol Can 2008; $30: 148-151$.

2. Flamm BL. Once a cesarean, always a controversy. Obstetrics and Gynecology. 1997 Aug 1;90(2):312-5.

3. Flamm BL, Newman LA, Thomas SJ, Fallon DE, Yoshida MM. Vaginal birth after cesarean delivery: results of a 5-year multicenter collaborative study. Obstetrics and Gynecology. 1990 Nov 1;76(5 Pt 1):7504.

4. Caughey AB, Shipp TD, Repke JT, Zelop CM, Cohen A, Lieberman E. Rate of uterine rupture during a trial of labor in women with one or two prior cesarean deliveries. American journal of obstetrics and 
gynecology. 1999 Oct 1;181(4):872.

5. Miller DA, Diaz FG, Paul RH. Vaginal birth after cesarean: a 10-year experience. Obstetrics and gynecology. 1994 Aug 1;84(2):255-.

6. Lydon-Rochelle M, Holt VL, Easterling TR, Martin DP. Risk of uterine rupture during labor among women with a prior cesarean delivery. New England Journal of Medicine. 2001 Jul 5;345(1):3-8.

7. Jones RO, Nagashima AW, Hartnett-Goodman MM, Goodlin RC. Rupture of low transverse cesarean scars during trial of labor. Obstetrics and gynecology. 1991 Jun 1;77(6):815-7.

8. Leung AS, Leung EK, Paul RH. Uterine rupture after previous cesarean delivery: maternal and fetal consequences. American journal of obstetrics and gynecology. 1993 Oct 1;169(4):945-50.

9. American College of Obstetricians and Gynecologists. ACOG Practice bulletin no. 115: Vaginal birth after previous cesarean delivery. Obstetrics and gynecology. 2010 Aug;116(2 Pt 1):450-63.

10. Society of Obstetricians and Gynaecologists of Canada. SOGC clinical practice guidelines. Guidelines for vaginal birth after previous caesarean birth. Number 155 (Replaces guideline Number 147), February 2005. International journal of gynaecology and obstetrics: the official organ of the International Federation of Gynaecology and Obstetrics. 2005 Jun;89(3):319-31.

11. Rozenberg P, Goffinet F, Philippe HJ, Nisand I. Ultrasonographic measurement of lower uterine segment to assess risk of defects of scarred uterus. The Lancet. 1996 Feb 3;347(8997):281-4.

12. Michaels WH, Thompson HO, Boutt A, Schreiber FR, Michaels SL, Karo J. Ultrasound diagnosis of defects in the scarred lower uterine segment during pregnancy. ObstetGynecol 1988; 71: 112- 120.

13. Rozenberg P, Goffinet F, Phillippe HJ, Nisand I. Ultrasonographic measurement of lower uterine segment to assess risk of defects of scarred uterus. Lancet 1996; 347: 281-284.

14. Asakura H, Nakai A, Ishikawa G, Suzuki S, Araki T. Prediction of uterine dehiscence by measuring lower uterine segment thickness prior to the onset of labor: evaluation by transvaginal ultrasonography. J Nippon Med Sch 2000; 67: 352-356.

15. Qureshi B, Inafuku K, Oshima K, Masamoto H, Kanazawa K. Ultrasonographic evaluation of lower uterine segment to predict the integrity and quality of cesarean scar during pregnancy: a prospective study. Tohoku J Exp Med 1997; 183: 55- 65.

16. Rozenberg P, Goffinet F, Philippe HJ, Nisand I. Thickness of the lower uterine segment: its influence in the management of patients with previous cesarean sections. Eur J ObstetGynecolReprodBiol 1999; 87: 39 45.

17. Gotoh H, Masuzaki H, Yoshida A, Yoshimura S, Miyamura T, Ishimaru T. Predicting incomplete uterine rupture with vaginal sonography during the late second trimester in women with prior cesarean. ObstetGynecol 2000; 95: 596- 600.

18. Sen S, Malik S, Salhan S. Ultrasonographic evaluation of lower uterine segment thickness in patients of previous cesarean section. Int J GynaecolObstet 2004; 87: 215-219.

19. Cheung VY. Sonographic measurement of the lower uterine segment thickness in women with previous caesarean section. J ObstetGynaecol Can 2005; 27: 674- 681.

20. Jastrow N, Antonelli E, Robyr R, Irion O, Boulvain M. Inter- and intraobserver variability in sonographic measurement of the lower uterine segment after a previous Cesarean section. Ultrasound ObstetGynecol 2006; 27: 420- 424.

21. Fukuda M, Shimizu T, Ihara Y, Fukuda K, Natsuyama E, Mochizuki M. Ultrasound examination of caesarean section scars during pregnancy. Arch GynecolObstet 1991; 248: 129- 138. 
22. Cheung VY. Sonographic measurement of the lower uterine segment thickness: is it truly predictive of uterine rupture? Journal of Obstetrics and Gynaecology Canada. 2008 Feb 1;30(2):148-51.

23. Swift BE, Shah PS, Farine D. Sonographic lower uterine segment thickness after prior cesarean section to predict uterine rupture: A systematic review and meta-analysis. Actaobstetricia et gynecologicaScandinavica. 2019 Jul;98(7):830-41

24. Martins WP, Barra DA, Gallarreta FM, Nastri CO, Filho FM. Lower uterine segment thickness measurement in pregnant women with previous Cesarean section: reliability analysis using two-and three-dimensional transabdominal and transvaginal ultrasound. Ultrasound in Obstetrics and Gynecology. 2009 Mar;33(3):301-6.

25. Mohammed AB, Al-Moghazi DA, Hamdy MT, Mohammed EM. Ultrasonographic evaluation of lower uterine segment thickness in pregnant women with previous cesarean section. Middle East Fertility Society Journal. 2010 Jul 1;15(3):188-9

\section{Notes}

fig.1

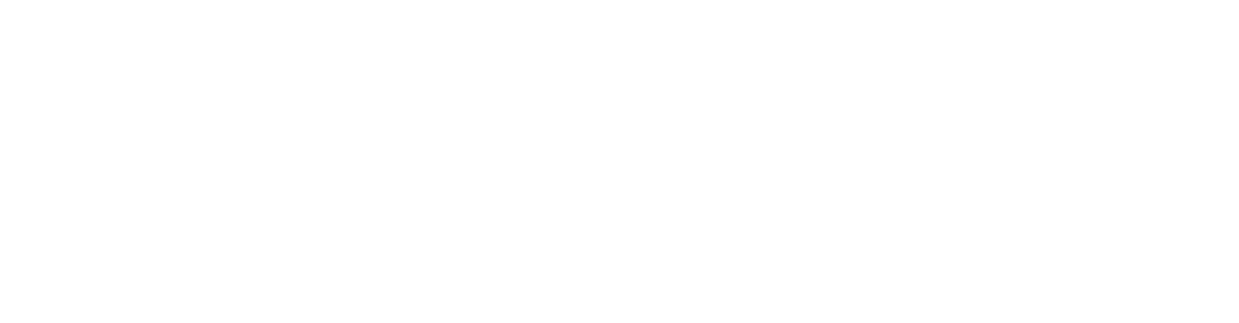


fig. 2

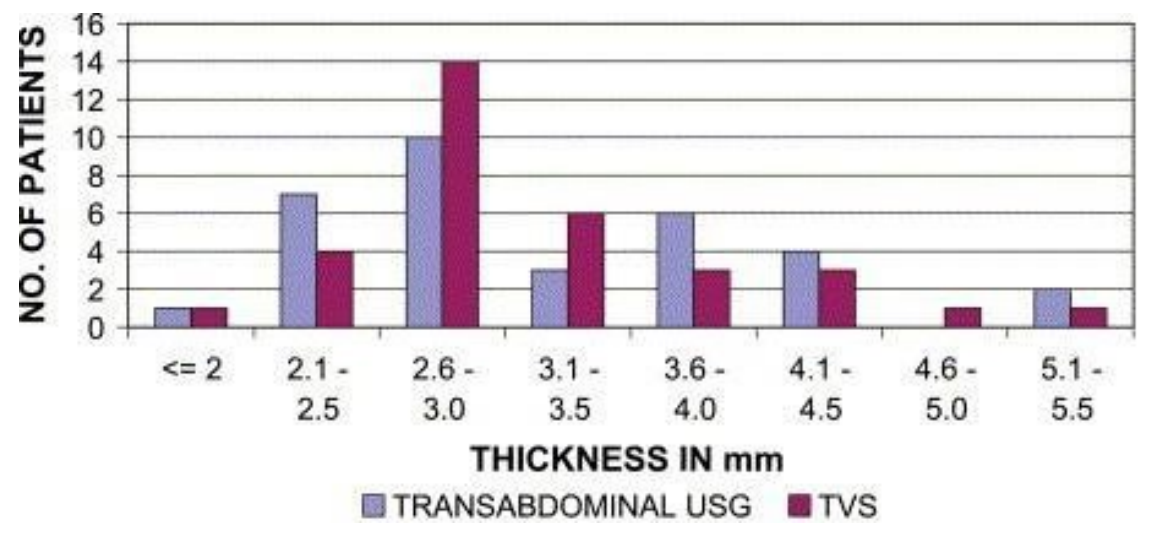

fig. 3

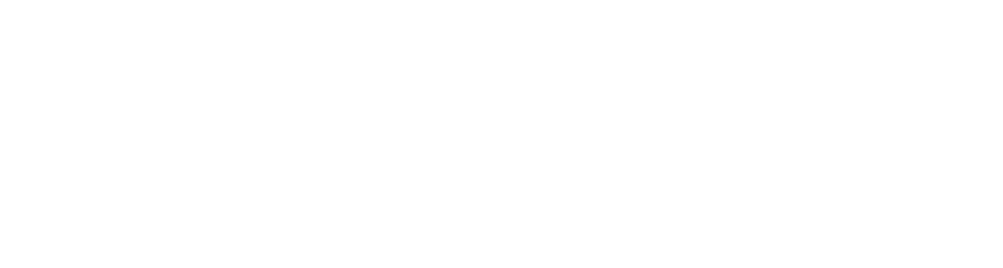

